\title{
Alternatives to PumpKIN: The ongoing development of ventricular assist devices for infants
}

\author{
Ryan R. Davies, MD
}

From the Department of Cardiovascular and Thoracic Surgery, UT Southwestern Medical Center and Children's Health, Dallas, Tex.

Disclosures: Author has nothing to disclose with regard to commercial support.

Received for publication June 26, 2018; revisions received June 26, 2018; accepted for publication June 27, 2018; available ahead of print Aug 10, 2018.

Address for reprints: Ryan R. Davies, MD, 1935 Medical District Dr, MC B3.410, Dallas, TX 75235 (E-mail: ryan.davies@utsouthwestern.edu).

J Thorac Cardiovasc Surg 2018;156:1642

$0022-5223 / \$ 36.00$

Copyright $(2) 2018$ by The American Association for Thoracic Surgery

https://doi.org/10.1016/j.jtcvs.2018.06.070

The availability and use of mechanical circulatory support devices in children has been expanding rapidly. There is still no option, however, for safe, durable, and dischargeable support in infants and small children weighing less than 15 to $20 \mathrm{~kg}$. The development of extracorporeal centrifugal and paracorporeal pulsatile devices intended for use in children has resulted in a dramatic improvement in outcomes in these complex cases. ${ }^{1}$ Challenges remain, however, and outcomes are far from ideal.

In adults, the transition to intracorporeal continuous-flow pumps resulted in dramatic improvements in risk profile and suvival. ${ }^{2}$ Similar improvements in the management of adolescents have been achieved with the use of adult pumps in progressively smaller children. ${ }^{3}$ The article by Olia and colleagues ${ }^{4}$ in this issue of the Journal describes the ongoing effort to extend these improvements to the smallest children.

Olia and colleagues ${ }^{4}$ have been developing a continuousflow ventricular assist device intended for intracorporeal insertion into infants as small as $3 \mathrm{~kg}$. Although the article describes preliminary animal work, it is encouraging. The largest barrier to the miniaturization of ventricular assist devices has been the propensity for hemolysis, as has been seen with the infant Jarvik 2000 pumps (Jarvik Heart, Inc, New York, NY). Researchers solved that problem by modifications that included an increase in the inflow cannula from $11 \mathrm{~mm}$ to $15 \mathrm{~mm}$, resulting in an increase in the lower end of the indicated weight range to $8 \mathrm{~kg} .^{5}$ In contrast, the PF4 prototype has an inflow cannula that is $5 \mathrm{~mm}$ in diameter, and it is intended for support of children as small as $5 \mathrm{~kg}$.

In the reported studies, there was very little hemolysis in animals with support times of more than 2 weeks when the device was run at speeds and flows appropriate for infant support. This is contrast to the early studies of the original infant Jarvik 2000, which had significant hemolysis and

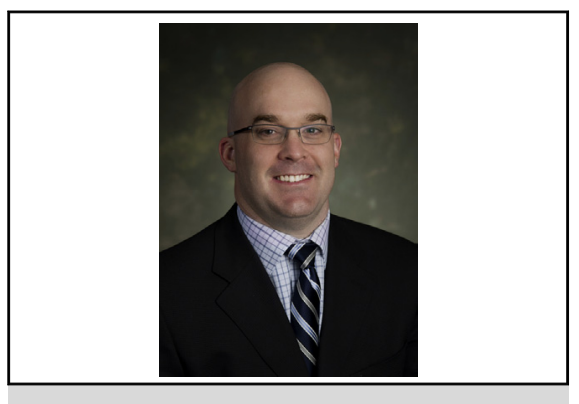

Ryan R. Davies, MD

Central Message

Ongoing development of infant ventricular assist devices suggests that further opportunities exist to provide mechanical support to the smallest children.

See Article page 1643.

damage to end organs during sheep support. ${ }^{6}$ Thus, although it is not a part of the current PumpKIN trial plan, this device has the potential to expand further the population of patients supported by intracorporeal devices. Olia and colleagues ${ }^{4}$ are to be congratulated on their persistence and their progressive improvements in pump design.

\section{References}

1. Fraser CD Jr, Jaquiss RD, Rosenthal DN, Humpl T, Canter CE, Blackstone EH, et al. Berlin Heart Study Investigators. Prospective trial of a pediatric ventricular assist device. N Engl J Med. 2012;367:532-41.

2. Jorde UP, Kushwaha SS, Tatooles AJ, Naka Y, Bhat G, Long JW, et al; HeartMate II Clinical Investigators. Results of the destination therapy post-Food and Drug Administration approval study with a continuous flow left ventricular assist device: a prospective study using the INTERMACS registry (Interagency Registry for Mechanically Assisted Circulatory Support). J Am Coll Cardiol. 2014;63: 1751-7.

3. Conway J, Miera O, Adachi I, Maeda K, Eghtesady P, Henderson HT, et al; Pediatric VAD Investigators. Worldwide experience of a durable centrifugal flow pump in pediatric patients. Semin Thorac Cardiovasc Surg. March 15, 2018 [Epub ahead of print].

4. Olia SE, Wearden PD, Maul TM, Shankarraman V, Kocyildirim E, Snyder ST, et al. Preclinical performance of a pediatric mechanical circulatory support device: the PediaFlow ventricular assist device. J Thorac Cardiovasc Surg. 2018;156: $1643-51$.

5. Adachi I, Burki S, Zafar F, Morales DL. Pediatric ventricular assist devices. J Thorac Dis. 2015;7:2194-202.

6. Adachi I, Burki S, Horne D, Costas GG, Spangler T, Jarvik R, et al. The miniaturized pediatric continuous-flow device: preclinical assessment in the chronic sheep model. J Thorac Cardiovasc Surg. 2017;154:291-300. 